\title{
UN EPISODIO DE VIOLENCIA EN EL BAKER: LA MUERTE DE TRES KAWÉSQAR EN BAJO PISAGUA (47²6'S/73³5'), 1931.
}

MAURICIO OSORIO P.

\section{RESUMEN}

Hacia fines de los años veinte y hasta mediados de los treinta, la vida social en el Baker se vió conmocionada por diversos hechos que daban cuenta de un clima de tensión y violencia donde los protagonistas eran la Estancia Posadas, Hobbs \& Cía. y los habitantes (colonos, ocupantes y gente en tránsito) del área. Uno de esos episodios -ocurrido en Bajo Pisagua- fue la muerte de tres miembros de un grupo alacalufe, alcanzados por disparos realizados por empleados de dicha estancia.

En este trabajo se intentará reconstruir lo sucedido, con el objetivo de acercarnos a una verdad histórica a partir de la contrastación de diversas versiones del hecho. Pero además se intentará una explicación contextual para la presencia indígena en el área, posiblemente conviviendo anónimamente con la emergente cultura de los pobladores del Baker y afrontando como ellos la dinámica impuesta por la explotación ganadera a gran escala en tierras fiscales arrendadas.

PALABRAS CLAVE: canoeros kawésqar, siglo XX, río Baker, Bajo Pisagua, violencia, movilidad.

\section{A VIOLENCE EPISODE AT BAKER RIVER: THE DEATH OF THREE KAWÉSQAR PEOPLE AT BAJO PISAGUA (47²6'S/73³5’), 1931.}

\begin{abstract}
Toward the last years of the twenties' and the mid thirties' the social life of Baker region was subject to several tense and violent situations protagonized by the Estancia Posadas, Hobbs \& Cía., on one hand and the pioneer of the area, on the other. One of these events concerned the killing of three alacalufe people by Estancia employees at Bajo Pisagua.

This paper will attempt to reconstruct the episode, with the aim of advancing to the historical truth by means of opposing different versions. A contextual explanation of the native's presence in the area is attempted, as they may have coexisted anonimously with the nascent culture of the Baker people and facing with them the dynamics of large scale entrepreneurial stockbreeding on rented federal lands.

KEY WORDS: kawésqar, canoe natives, XX century, Baker river, Bajo Pisagua, violence, mobility.




\section{AÑOS DE TENSIÓN EN EL BAKER}

La historia de la colonización del Baker $\left(47^{\circ} \mathrm{S}\right)$ registra varios momentos donde la violencia fue protagonista. Entre 1909 y 1911 se cree que Carlos von Flack, a la sazón arrendatario de tierras en la zona, habría dirigido atropellos a ocupantes del área, llegando incluso a producirse atentados contra la vida de algunos pobladores. ${ }^{1}$

Era normal en aquella época que los conflictos entre pobladores y estancieros tanto en Chile como Argentina, se resolvieran con el ataque $y / o$ asesinato de alguno de los involucrados. Administradores de estancias, peones o jefes de familia murieron en esta llamada ley del más fuerte. Cuando la ley lograba ser aplicada, normalmente se sancionaba con más dureza a peones, pobladores particulares y familias pobres que transitaban en el extenso territorio. ${ }^{2}$

En la región del Baker el proceso de ocupación y poblamiento se desarrolló tanto como consecuencia del accionar de Compañías ganaderas que consiguieron en distintas épocas concesiones de extensas áreas, y que requerían de importante contingente de trabajadores para las diversas faenas; como por la instalación espontánea de familias campesinas en tierras ribereñas de ríos y lagos, las que buscaban asentarse temporal o definitivamente para desarrollar explotaciones ganaderas familiares y de subsistencia (Osorio 2007). Es así que el proceso de ocupación sostenida de terrenos posterior a la liquidación de la Compañía Explotadora del Baker ocurrida en 1908, dará inicio a un sinnúmero de episodios de violencia, simultáneamente al proceso de reorganización empresarial para explotar las tierras en el área.

En este contexto general, a inicios de los años veinte la Estancia formada por el capitalista Hobbs y otros asociados para hacerse cargo de una nueva concesión en el Baker, determina que uno de sus socios, el ciudadano argentino Esteban Lucas Bridges, asuma su administración, justamente debido a que el administrador anterior, de apellido Wood, había

1 Archivo Sociedad Historia y Geografía de Aysén, carpeta Baker.

2 Pomar (1920) consigna hechos de sangre en ambos lados de la frontera cuando reseña antecedentes de algunos decretos relativos al poblamiento de Valle Simpson. Por su parte autores argentinos como Aguado y Maggiori recogen historias de violencia en sus trabajos. sido asesinado en un confuso incidente años antes (Martinic 1977). Después de varios años de trabajo, Bridges logra regularizar la actividad productiva de la Compañía. Durante su administración, que instauró una política general de buena vecindad con los colonos asentados en el área -salpicada de episodios hostiles y presiones a pobladores para que abandonaran sus posesiones- la conflictividad general en la zona disminuye.

En todo este cuadro social, la presencia de grupos canoeros en el extremo sur occidental del área de actividad de la Compañía ganadera liderada por Bridges, ha sido considerada como marginal y anecdótica, siendo su principal referencia el episodio de violencia en que tres indígenas pierden la vida, relatado por el mismo Bridges en sus memorias y que forma parte además de la memoria oral de los habitantes del espacio cultural del Baker. Es probable que la filiación étnica de estos grupos sea kawésqar, agrupación septentrional del pueblo alacalufe, cuyo territorio en la Patagonia Occidental estaba comprendido entre la boca meridional que conduce al canal Sarmiento por el sur y el margen sur del golfo de Penas (Aguilera y Errázuriz 1996). Basados en testimonios orales (recogidos por Gómez y Cheuquemán 2004) que refieren la presencia de grupos canoeros provenientes de Puerto Edén, se sugiere lo anterior.

El presente trabajo se propone analizar dicho episodio, contrastando los relatos escritos y orales que lo han mantenido vigente en la memoria histórica de la región de Aysén, y aportando con los antecedentes recabados en torno a la versión oficial del suceso, elaborada por las autoridades de la época, la Intendencia de la Provincia de Aysén y Carabineros de Chile.

A partir de las circunstancias que originan este episodio de violencia y sus consecuencias inmediatas y posteriores, se reflexiona en torno a la presencia de familias kawésqar en el canal Baker y zonas aledañas, relacionándola con el enclave occidental del puerto Bajo Pisagua y eventualmente con las familias que poco a poco irán poblando el área.

\section{1. El episodio}

A principios de 1931 las instalaciones que la Estancia Posadas, Hobbs y Cía. mantenía en Bajo Pisagua, en la desembocadura del río Baker, se 


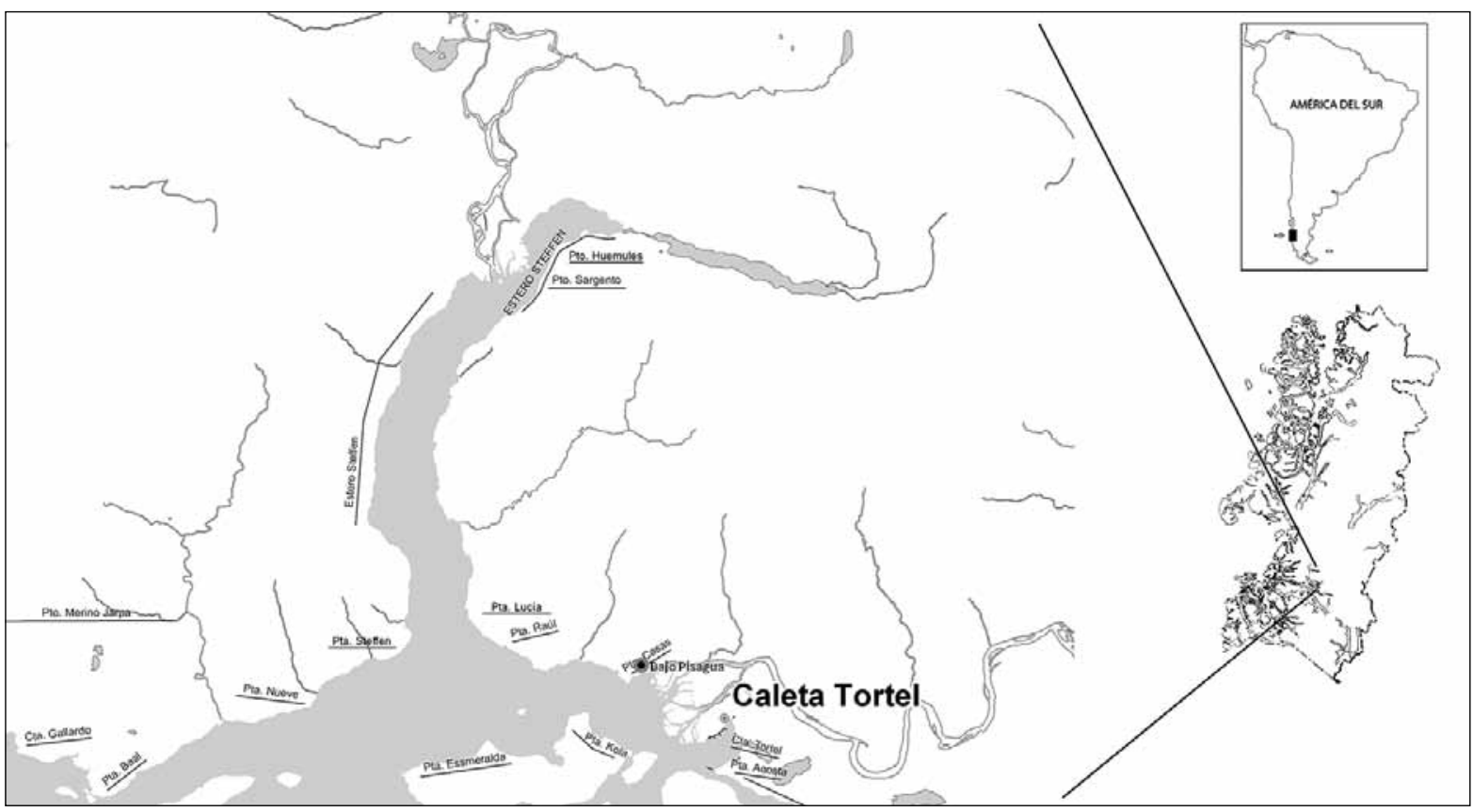

Fig. 1 Ubicación de Bajo Pisagua. (Elaborado por Gustavo Saldivia).

vieron alborotadas por un enfrentamiento armado entre empleados apostados en aquella sección y un grupo de personas que se movilizaban en dos canoas de estilo indígena con rumbo a dicho lugar, para solicitar alimentos o intercambiarlos por pieles, producto de cacerías practicadas en los canales. El intercambio de disparos dejó como saldo tres personas muertas, todas pertenecientes al grupo de navegantes, identificados por los empleados como alacalufes.

Días después, carabineros apostados en la sección La Colonia de la estancia y el mismo Esteban Lucas Bridges, su administrador, se enteran de los sucesos, de boca de los mismos empleados que se trasladan río arriba para dar cuenta de lo acontecido. Inmediatamente deciden trasladarse al lugar para verificar la situación, participando incluso en la inhumación de las víctimas. El resto del grupo alacalufe se retira del área para no volver nunca más. Carabineros realiza una investigación dirigida por el prefecto provincial de la policía uniformada, en la que se establece que los trabajadores de la Estancia no tienen responsabilidad penal ni moral por la muerte de las tres personas, ya que actuaron en defensa propia y contra un grupo de personas incivilizadas.
Estos son los hechos. La descripción presentada ha sido elaborada a partir de las versiones recogidas y que serán analizadas en este trabajo; la primera de ellas, difundida por diversos medios desde mediados de los años treinta del siglo pasado, corresponde al relato de Esteban Lucas Bridges quien no sólo la consignó en sus memorias inéditas sobre su vida y trabajo en el Baker, sino que la relató a personas que posteriormente la incluyeron en sus propios escritos, como veremos más adelante. Existe también una versión recogida por la memoria oral de los pobladores del Baker, que conocemos gracias a recientes trabajos de recopilación histórica. Finalmente, se cuenta con una versión gubernamental del acontecimiento, recogida en documentos públicos emanados desde distintas reparticiones públicas de la época como la Intendencia de la Provincia de Aysén, organismo que desde el inicio recibe información sobre el caso desde el Baker; y Carabineros de Chile, institución que realiza una investigación sumaria del hecho. Ambos organismos informarán lo acontecido al Ministerio del Interior.

De estas tres versiones, sólo la primera ha sido considerada por la historiografía hasta ahora, resultando de este modo parcial la comprensión del hecho. En cambio, la versión alojada en la memoria oral sólo ha sido rescatada en dos momentos: a 
comienzo de los ochenta del siglo pasado (Hartmann 1982) y recién iniciado el presente siglo, por investigadores locales de la comuna de Cochrane (Gómez y Cheuquemán 2004). Se analizarán y compararán en primer término ambas versiones, las que se han encargado de mantener viva la historia de estas muertes, con intencionalidades diversas, como veremos. Posteriormente se presentarán los antecedentes que constituyeron la versión oficial de lo sucedido en Bajo Pisagua, dando de este modo luz sobre un hecho que resultó ser uno de los más importantes de aquel año 1931 para la población y autoridades del recién creado Territorio de Aysén, a juzgar por los oficios emanados desde la Intendencia informando al Ministerio del Interior sobre hechos de sangre en la zona ${ }^{3}$.

\section{LAS VERSIONES CONOCIDAS DEL EPISODIO}

En la literatura producida dentro y fuera de la región se ha descrito el episodio ocurrido en Bajo Pisagua como un enfrentamiento entre un grupo de indígenas alacalufes y empleados de la Estancia Posadas, Hobbs y Cía, destacados en las instalaciones de Bajo Pisagua. Los relatos de Martinic (1977) e Ivanoff (2004) describen el hecho basándose en la versión -inédita aún- que Lucas Bridges escribiera. De este modo, se busca graficar las dimensiones del sacrificio que los hombres a cargo del emprendimiento ganadero liderado por Bridges, debieron hacer para sacar adelante dicha iniciativa. Un hecho de violencia, por aislado que pueda parecer, siempre contribuye con una cuota de dramatismo en la construcción histórica de un proceso colonizador con dimensiones productivas. Otros dos escritos (Campos 1986; Tschiffely 1945) tratan el hecho a partir de la misma fuente, pero cada uno de ellos lo relata en función de sus propios intereses literarios.

Por su parte, el escrito de Elias (1997) y las recopilaciones de Hartmann (1982) y Gómez

3 Correspondencia recibida año 1931, Ministerio Interior. Archivo Nacional de la Administración (ARNAD), Fondo Ministerio del Interior, Sección Gobierno, Minutas, vol 7950. Los otros hechos que la Intendencia informó aquel año fueron la muerte por inmersión de tres personas en el río Aysén, quienes se desplazaban en un bote; y una riña entre empleados de la Sociedad Estancia Posadas Hobbs y Cía, en Bajo Pisagua, acaecida en octubre, donde muere un empleado de nacionalidad alemana. y Cheuquemán (2004) recogen otra versión del mismo hecho, entregándola al lector ya sea como testimonios de memoria oral o como construcciones literarias, abriendo de este modo otras posibilidades de interpretación histórica.

Al realizar una lectura preliminar de todos los registros mencionados, se configuran una serie de preguntas: ¿Cuándo exactamente ocurrió aquel enfrentamiento? $\mathrm{O}$ de otro modo: ¿por qué se plantea como difusa la fecha en que éste ocurrió?; ¿por qué se produjo, quién realmente lo inició?; ¿dónde fueron enterrados los muertos?; ¿qué fue del parte de los carabineros que menciona una de ellas y qué dirá aquel documento policial?; ¿por qué se considera la versión de Bridges como definitiva si el mismo autor sugiere que existe una investigación policial?

II.1 La versión difundida en la historiografía oficial

En el relato inédito Sinopsis del trabajo realizado en el Baker durante 28 años escrito por Bridges, presumiblemente a mediados de los años cuarenta ${ }^{4}$, podemos leer:

Sin embargo, golpe tras golpe caían sobre nuestra Compañía. El Ian Lucas II acababa de zarpar rumbo a San Carlos esperando volver en cuatro días, cuando dos canoas de alacalufes, cuyo jefe era mestizo, aparecieron en el Bajo Pisagua, armados con dos rifles, pero una barricada de roca había sido construida previendo estos ataques. Los dos hombres que se habían quedado allí, viendo la actitud amenazante de los indios, les gritaron que se fueran y por último les tiraron un tiro sobre sus cabezas para asustarlos; esto los incitó aún más pues creyeron que sus enemigos tenían mala puntería. Una batalla pronto comenzó a librarse y esta terminó con la muerte de tres del grupo atacante, incluyendo el cabecilla. Recién entonces los otros se retiraron.

Cuando me enteré de la noticia fui con el Mayor y el Subteniente de Carabineros quienes hicieron las investigaciones necesarias, y sepultamos a las víctimas. Nuestros dos hombres: un escocés y un chileno habían cumplido heroicamente con

4 La versión original en inglés fue igualmente revisada -gracias a la colaboración del antropólogo Joaquín Bascopé- y al constatar que la traducción se ajustaba al original, se prefirió trabajar con ella, en atención a que es la que ha sustentado el trabajo historiográfico posterior. 
su deber, pero después de este ingrato episodio lo que querían era irse de esta región. Todo este asunto me entristeció mucho, pues mi padre hace 70 años entró en Tierra del Fuego con un grupo y estuvo con los yaganes. Esta fue la primera vez que un nativo había muerto en manos de algunos de nosotros o nuestros empleados. Pero yo tenía que seguir.

Este es el texto íntegro referido al episodio que analizamos. Como contextualización cabe mencionar además que sigue a este relato, otro donde Bridges describe el asesinato de un empleado alemán en Bajo Pisagua a manos de un trabajador (cocinero) chilote de apellido Pérez, hecho que ocurre un tiempo después del primero, aunque no precisa fecha ${ }^{5}$. Resulta llamativo que a diferencia del episodio que involucra la muerte de los tres indígenas, el asesinato del empleado alemán es relatado por Bridges no sólo en Sinopsis..., sino que además en otro escrito inédito llamado Memorias del Baker, donde no se recoge el primero ${ }^{6}$. Tanto en los relatos historiográficos como los referenciales, ambos hechos de violencia son tratados como episodios conectados en tanto hechos de sangre acaecidos en un mismo lugar, aunque -sugieren- en distintos años.

El primer trabajo que conocemos, donde se recoge la versión que se ha transcrito (Martinic 1977), la utiliza para ilustrar el drama que llegó a tener la empresa liderada por Bridges, que a juicio de este autor asumió caracteres de tragedia.

Décadas más tarde, Ivanoff (2004) reproducirá íntegro el mismo relato, explicando antes que una especie de maleficio pesaba sobre los intereses magallánicos en el Baker:

Pero el territorio del Baker parecía tener un maleficio para los empresarios magallanicos [sic]. Las cosas malas venían frecuentemente y los inconvenientes se encontraban en cada recodo del río. Uno de los episodios fue la muerte de un grupo de alacalufes en manos de empleados de la compañía. (p. 136)

Una vez referida la versión de Bridges, Ivanoff argumenta que tanto el enfrentamiento entre empleados y alacalufes como el asesinato del empleado alemán [...]han dado pie a diferentes leyendas en el Baker y a innumerables historias, agregando

\footnotetext{
Se trata justamente de la riña mencionada en nota anterior. 6 Para el presente trabajo se ha seguido la publicación de ambos textos en la web www.patlibros.org.
}

para el caso que nos interesa que: Siempre se ha aumentado el número de alacalufes muertos por los trabajadores de la estancia Baker [...] (p. 139)

Más adelante, la investigadora afirma que: No hay una fecha clara sobre estos acontecimientos, pero el segundo [el asesinato del empleado alemán] debe haber transcurrido en los primeros años de la década de 1930[...]; y remata el tratamiento de estos hechos con un nuevo testimonio sobre los mismos, escrito por uno de los protagonistas del episodio que resultó en el asesinato del empleado alemán. Dicho relato será analizado más adelante.

Respecto a la versión de Lucas Bridges, se puede observar que los investigadores la recogen como relato fiel de la realidad, sin profundizar en los vacíos de información de la misma, como el año en que ocurrió, dónde fueron sepultados los cadáveres, de quién recoge Bridges la versión de los hechos y por qué el estanciero no se refiere a los resultados de la investigación de los carabineros que lo acompañaban. Antes de avanzar algunas aproximaciones a estas interrogantes, se analizarán los diversos aspectos implícitos en ellas.

Bridges comienza indicando que la lancha Ian Lucas II había zarpado de Bajo Pisagua con rumbo a Puerto San Carlos, para retornar 4 días después a la desembocadura del Baker. En el intertanto habrían aparecido dos canoas de alacalufes en Bajo Pisagua.

Esta primera parte del relato nos entrega el espacio temporal inmediato en que se habrían desencadenado los hechos: cuatro días. También se precisa la filiación étnica de todos los protagonistas: canoeros indígenas, específicamente alacalufes, liderados por un "mestizo" por un lado; escocés y chileno, sus dos empleados por el otro.

Luego, Bridges indica que los indígenas portaban dos armas de fuego, específicamente rifles. No es tan preciso sin embargo, respecto de las armas de fuego de sus empleados. Sólo indica que ellos realizaron un tiro de advertencia y luego se armó un tiroteo, pero no es posible saber si ambos empleados estaban armados o era sólo uno de ellos el que tenía arma. Tampoco se precisa qué tipo de armas había en las casas de Bajo Pisagua y menos se puede saber cuánta munición existía en el lugar. Por otra parte, el estanciero es escueto al explicar las circunstancias de la batalla como la califica, pero su pluma busca sugerir que los indígenas aparecen de improviso, armados y en actitud amenazante. ¿Significará 
aquello que nunca antes habían aparecido estos $\mathrm{u}$ otros grupos canoeros en el área? Este parece no ser el caso pues el mismo Bridges indica que en un lugar del puerto se habría construido una barricada de rocas como prevención de ataques de este tipo.

Ahora bien, volviendo al inicio de la refriega, Bridges sugiere que la actitud amenazante de los indígenas provoca la reacción de sus empleados en el sentido de exigir a gritos el retiro de los navegantes. $\mathrm{Y}$ aunque afirma que el primer tiro fue percutado por uno de sus empleados, el estanciero sindica a los alacalufes como los atacantes.

En relación con la fecha de los acontecimientos, al revisar detenidamente los dos escritos inéditos de Lucas Bridges es posible constatar que en Sinopsis..., el estanciero indica que la muerte del empleado alemán a manos del cocinero Pérez ocurre Un año o dos más tarde después de los acontecimientos que acabo de narrar[...], refiriéndose a la refriega en la que mueren los tres indígenas. En cambio, en Memorias del Baker entrega una fecha relativamente exacta del asesinato del trabajador alemán: Era hacia fines de octubre de 1932 cuando dejé a cuatro hombres en Bajo Pisagua con suficientes provisiones para pasar el invierno[...], y prosigue con el relato del crimen 7 . A partir de la integración de los datos se infiere que la muerte de los indígenas habría ocurrido en 1931 o 1930.

En otro documento escrito por Bridges ${ }^{8}$ en 1934 (fecha mucho más cercana a los hechos), y cuya motivación dice relación con solicitar modificaciones al contrato de arrendamiento de tierras de la Sociedad Ganadera, se describen someramente los hechos arriba referidos como razones poderosas que fundamentan la solicitud de cambiar la vía para

7 A partir del hallazgo de los oficios de la Intendencia que informaban un nuevo hecho de sangre en Bajo Pisagua en octubre de 1931, se pesquisó la providencia 13030 evacuada por el Ministerio del Interior, logrando dar con los antecedentes relacionados a este segundo hecho de violencia, ocurrido el 14 de octubre de aquel año, lo que desmiente la fecha consignada por Bridges en su escrito. No es posible determinar cuál fue la motivación del estanciero para separar temporalmente ambos acontecimientos. Si se argumentara dificultad para recordar por parte del estanciero, entonces se debería relativizar todas las demás fechas que entrega en sus escritos.

8 Carta solicitud de modificación contrato de arrendamiento, dirigida al Ministro de Tierras y Colonización. Recepcionada en el ministerio el 8 de mayo de 1934. Archivo Sociedad de Historia y Geografía de Aysén, carpeta Baker. sacar la producción de la estancia; se puede leer en relación al episodio que interesa: Hoy día ya no es posible conseguir gente para destacarla en Bajo Pisagua, especialmente después del ataque a mano armada que hicieron los indios el año antepasado (1932), ataque que hubo de ser repelido dando muerte a tres individuos.

Nuevamente Bridges sindica a los alacalufes como atacantes de las instalaciones de Bajo Pisagua y a los empleados como meros defensores de sus propias vidas y de los intereses de la Compañía. La muerte de los tres indígenas aparece en este breve relato como una consecuencia cuyos responsables fueron los propios indígenas. Y en el contexto del documento citado, el ataque a mano armada es argumento para justificar la dificultad de apostar personal a cargo del puerto Bajo Pisagua, fundamentando así la solicitud de trasladar la ruta de tráfico de la Compañía hacia el lago Buenos Aires (actual General Carrera).

Respecto de la sepultación de los cadáveres cabe preguntarse si ello habría ocurrido en el cementerio que hoy reconocemos como Isla de los Muertos, a la sazón conocido por el autor, que en otro pasaje menciona la muerte de cien trabajadores de la antigua Compañía ganadera que estuvo en el Baker ${ }^{9}$; o en otro sitio elegido arbitrariamente para la inhumación en las cercanías del lugar donde los indígenas yacían muertos. En cualquiera de los dos casos: ¿Qué tipo de sepultura se les habrá dado a los indígenas?, ¿cristiana?, ¿anónima, sin referencias ni identificación que permitiera recordarles en adelante? Nada dice el estanciero al respecto. Sólo se afirma que hubo inhumación.

Acerca de la versión de los hechos, parece ser que Bridges relata lo sucedido combinando lo que los empleados implicados relataron, junto con lo que él mismo observa y en lo que debe participar al momento de llegar al lugar. Pese a que menciona que carabineros hicieron las investigaciones necesarias, no hace alusión a parte policial alguno, dejando la duda respecto a si existió algún documento oficial sobre el hecho o qué curso siguió la investigación de los mismos. Para el estanciero, todo termina allí mismo, con el entierro de las víctimas, pues la empresa tenía que continuar.

9 De hecho el relato finaliza con esa referencia. 
II. 2 Otros relatos: epistolario, testimonios orales, literatura

Como hemos dicho más arriba, Ivanoff recoge en su trabajo otro relato. Se trata de una carta escrita por Eduardo Lancaster Soly, que estuvo involucrado en la riña y fue testigo directo de la muerte del empleado alemán a manos del trabajador chilote e indirecto -como Bridges- del enfrentamiento con los indígenas. ${ }^{10}$ En el documento dirigido a su hijo y fechado en 1972, Lancaster aclaraba los dichos de un artículo aparecido en la prensa regional que le sindicaba como responsable de ambos episodios de violencia. Transcribiremos aquí lo que escribió respecto al enfrentamiento que analizamos:

1. Bajo Pisagua jamás fue saqueado por los alacalufes y en mediados de 1930 vinieron en visitar Pisagua. Unos días después, mas tarde dejando un escocés McCauly y un chilote Chodill a cuidar, subimos al río a San Carlos en la lancha chica. De regreso supimos que los alacalufes atacaron la población, pero fueron rechazados con rifles por estas dos personas. 3 alacalufes murieron y nunca más volvieron ${ }^{11}$ (en Ivanoff, op. cit: 140)

Esta versión comienza aclarando que los indígenas "no saquearon" Bajo Pisagua, sino que lo visitaron. Los hechos según este testigo se habrían producido en el intertanto que un grupo de ellos -él incluido- suben desde Bajo Pisagua a San Carlos, dejando sólo a dos empleados cuidando las instalaciones aguas abajo, lo que coincide con el relato de Bridges. Lancaster sitúa el episodio a mediados de 1930 y pese a decir que los indígenas visitaban el puerto, luego los responsabiliza de atacar las instalaciones siendo repelidos con rifles por los empleados. Sin embargo no informa que los alacalufes estuviesen armados, sólo que atacaron.

Como se ve, la versión de Lancaster también coloca a los indígenas como atacantes sorpresivos, mas no como saqueadores, y al igual que Bridges no deja espacio a considerar una eventual relación o intercambio entre éstos y los empleados de la estancia que pudiese explicar la incursión de los primeros al lugar.

10 La investigadora indica que tuvo acceso a la misiva de parte de la familia del autor.

11 Ivanoff transcribe el texto de la carta respetando la grafía usada por su autor.
A mediados de 1982, el estudiante de arquitectura Peter Hartmann entrevistó a pobladores del Baker bajo, en el marco de su práctica profesiona. Entre los diversos temas que dos de los entrevistados abordaron surgió el caso de Bajo Pisagua. Hartmann, presentó en su informe de práctica un breve texto basado en uno de estos testimonios, el de Jorge Chodil M.:

Los Alacalufes en 1930 llegaron 2 veces hasta Bajo Pisagua donde les daban los desperdicios (Jorge Chodill M., antiguo poblador del Baker). Un cabo Quezada de Carabineros les ofreció un buen banquete en Tortel; al no estar presente Quezada, los Chonques o Alacalufes volvieron saludando; siendo recibidos a balazos por Lancaster uno de los tres Misters que manejaban las bodegas. Cayeron 11 Alacalufes[...] Los sobrevivientes nunca más volvieron[...] vivían en Pto. Edén donde cambiaban pieles y mariscos por pan duro y alcohol: quedan poquitos[...] (J. Chodill) ${ }^{12}$ (Hartmann, 1982: 13)

El texto presenta un cuadro muy distinto a la versión de Bridges. En primer lugar hay una fecha clara, que coincide con la testimoniada por Lancaster, 1930. Luego la indicación de dos incursiones de los alacalufes -denominados por el poblador Chonques $^{13}$ - al puerto; dos momentos distintos en que un mismo grupo -al parecer- se acerca a las casas de la compañía donde se les daban sobras de alimentos. Luego se relata la intervención de un carabinero de apellido Quezada, que les ofrece un banquete. Esto habría sido durante la primera incursión. Cuando los indígenas vuelven, el carabinero ya no está y se los recibe a balazos. El testimonio sindica al empleado Lancaster - uno de los encargados de las instalacio-

12 Las negritas indican las citas testimoniales de los entrevistados por el autor, que en el original aparecen en cursiva y entrecomillado.

13 Según Cárdenas (1996) el término chonque es variante de chonqui, adjetivo que refiere a los gentiles o antiguos indígenas. Este autor atribuye su etimología a la palabra $\mathrm{CHON}$ o CHONK que en lengua canoera significaría "ser humano, nosotros". Registros etnográficos inéditos recogen un uso del término en localidades tan distantes como Melinka (Saavedra 2002) y Tortel (Osorio 2009), como adjetivo calificativo de connotación negativa, significando filiación étnica primitiva. Sin embargo, también se han registrado resignificaciones positivas del término entre jóvenes de la misma localidad de Tortel, donde ha surgido una agrupación cultural que lleva por nombre CHONKES, recuperando el término como símbolo de tradición indígena canoera. 
nes- como el autor de los disparos y responsable de once muertes. El relato finaliza indicando que los sobrevivientes nunca más volvieron al área, afirmación que también coincide con lo expresado por el mismo Lancaster, y que eran nativos provenientes de Puerto Edén.

Ahora bien, para el presente trabajo, se ha tenido a disposición la transcripción literal de la entrevista que Hartmann realizara a otro de los pobladores del Baker, Reinaldo Sandoval Cifuentes. Dicho testimonio es de gran interés en general y particularmente en lo tocante al tema que aquí se analiza:

Cuando supieron que llegaba gente ahí de aquí, se venían ellos... no ve que los corrió Lancaster a bala Lancaster mató como 11

Porque antes de eso vino un Cabo de afuera, el Cabo Quezada; los vio a los indios que llegaban pobres a pedir ahí, entonces se fue para afuera; cuando estuvo allá afuera pidió permiso para venir $y$ traerles regalos a los indios y darles un buen banquete en Tortel; si salieron civilizados dice.

Le dieron permiso, trajo de todo; estuvo unos días con los indios como 8 ó 10 días, no sé cuantos. El Cabo Quezada está en Osorno. Del año no me acuerdo. Pero no hace mucho tiempo que vino uno de allá, traía un informe de Quezada cuando él había estado en Pisagua

Entonces después, Quezada cuando se fue para afuera, al poco tiempo vinieron los indios, estaba Lancaster; Lancaster se atrincheró más arriba, ahí estaban cajones de balas y todo[...] y ahí les empezó a tirar y los mató; mató a unos cuantos, los otros arrancaron. Vuelta Quezada a venir a [...] sacar el informe de los alacalufes[...] después han venido, pero ¿ahora ya no vienen?

El testimonio de Sandoval coincide en gran parte con el de Chodil antes citado. Sin embargo, hay algunos detalles más sobre la relación entre el carabinero y el grupo alacalufe. El funcionario policial habría visto la pobreza de los indígenas y solicitó permiso (no se aclara a quién) para volver y entregarles regalos y darles un buen banquete en Tortel donde pasó varios días junto al grupo. Ante esta atención, los alacalufes habrían vuelto en otra oportunidad, pero el carabinero no se encontraba ya, siendo recibidos con disparos por el empleado Lancaster, sindicado nuevamente en esta versión como causante de once muertes. El testimonio fina- liza indicando que ante estos hechos el carabinero Quezada debió regresar para sacar el informe de los alacalufes, lo que parece referir a una investigación realizada por la policía, coincidiendo si es así, con el comentario del mismo Bridges al respecto. Lo que ambos testimonios contradicen abiertamente de la versión Bridges es el ataque sorpresivo de los canoeros, pues afirman que la sorpresa fue administrada por el empleado Lancaster, quien dispara directamente a los indígenas.

Pocos años atrás, fueron publicados dos relatos que demuestran la permanencia del suceso en la memoria oral de los habitantes del Baker (Gómez y Cheuquemán 2004). El primero corresponde a Eudomila Fuentes e Isidro Alarcón quienes relatan así el episodio:

En esos años habían hartos 'chonques', alacalufes que se movían desde el Estrecho de Magallanes hasta los canales cercanos a Caleta Tortel, que hacían sus campamentos con cueros de lobo marino.

Era gente buena. Andaban en canoas y se acercaban a los gringos a cambiar pieles de nutria por comida.

Una vez se arrimaron como siempre a la lancha de la Estancia que iba a Pisagua y seguramente los gringos ya estaban cansados de los indios y les dispararon para que no los molestaran más, quizá si sería para matarlos o no, la cosa es que los chonques también les tiraron unos tiros porque andaban trayendo armas y gente que no era india. Así que al final igual nomás los mataron[...] (p. 21)

El relato afirma de entrada la presencia en el área, de indígenas denominados por ellos chonques o alacalufes, que se desplazaban desde el sur a las cercanías del canal Baker y desembocadura del río homónimo, estableciéndose en campamentos y buscando realizar intercambio comercial con los empleados de la estancia. Este es un antecedente clave que diferencia esta versión de la difundida por Bridges. Explicaría las incursiones de grupos canoeros hasta Bajo Pisagua, contradiciendo la versión de un ataque sorpresivo. Ahora bien, el relato sitúa los acontecimientos no en las casas, sino en el mismo río donde las canoas se acercaron a la lancha de la compañía, pero los empleados quisieron alejarlos disparándoles primero, como advertencia; luego se produjo el incidente pues los indígenas respondieron también con disparos. Como resultado se indica la 
muerte de indígenas sin referencia a cantidad de víctimas.

El segundo testimonio pertenece a José Haro Márquez, quien recuerda:

Además de la cosa esa de Chapoco, tenían otras más de antes: tres chonques que ellos mismos habían matado. No ven que llegaban todo el tiempo los indios ahí para cambiarles cosas de comer, y dicen que ellos ya estaban aburridos y decidieron matarlos, a meterles bala y alcanzaron a matar a tres [...].

Los chonques andaban en canoítas que hacían de madera así nomás forradas con piel de lobo de mar. Andaban varios y según dicen andaba también gente civilizada, gente que era muy diabla y se metía con los indios porque andaban arrancando de la justicia. Esto era lo que decían los gringos.

Con los gringos de la estancia andaba un tal Chodil, de esos antiguos que trabajaba en la Compañía. Iban navegando por el río cuando vieron a los chonques, así que se decidieron a dispararles y como andaba gente blanca con los indios, estos igual dispararon. Pero como los de la Compañía eran más y mandaban a sus trabajadores, no tuvieron problemas para matarlos.

Después contaban que por eso tuvieron mal a la Compañía, multados, para que no maten a alguno otra vez, porque esos eran los verdaderos hijos del país, así que no podían matar a ninguno. Bueno, eso era lo que decían ellos, porque igual muchos desaparecieron y también gente blanca que quería ocupar algún campito por ahí. (p. 22)

Esta versión coincide en lo grueso con la anterior, en cuanto al intercambio regular de productos entre indígenas y empleados de la Sociedad Hobbs y Cía. Al tipo de embarcaciones usadas por los primeros, al lugar donde ocurre el enfrentamiento y a la presencia de mestizos o blancos entre los indígenas. Sin embargo, este testimonio afirma que los empleados de Bridges habrían decidido matar a los chonques, aburridos ya de su constante presencia. Esta versión también indica el número de indígenas que murieron en la refriega. Finaliza el testimonio con una reflexión en torno al accionar posterior de las autoridades que habrían "multado" a la compañía ganadera por estos y otros hechos de violencia. Por otra parte, esta versión conecta la muerte de los alacalufes y la riña entre empleados, como dos hechos que forman parte de una escalada de violencia protagonizada por algunos empleados extranjeros de la Estancia, con cierta intencionalidad.

Finalmente debemos consignar tres variantes escritas en clave literaria. La primera pertenece a A. F. Tschiffely, quien en su libro relata la historia oída del mismo Bridges cuando le conoce y entrevista en su casa de Entrada Baker hacia 1937. Bridges le debe haber hablado de muchas anécdotas, sacrificios y peripecias vividas durante su trabajo en el Baker, entre las que estaban la muerte de los indígenas y el asesinato del empleado alemán a manos del cocinero chilote en las instalaciones de Bajo Pisagua.

Transcribiremos aquí la versión de Tschiffely conservando el idioma inglés: ${ }^{14}$

With him he has several Europeans, including three or four Englishmen and Scotsmen. Since I was there, the foreman, a Hardy Scot, has died; how is unknown to me. His predecessor gave up his job after a fight with Indians during which, without being aware of it, he killed two women.

Left alone, together with a German, at an outpost near a lake he noticed some Indians approaching in a dug-out canoe. Presently, two shots echoed over the water, which made him run into the hut to fetch his rifle and to call out his companion. Lying down behind some rocks, the two White men opened fire, which made the Indians retreat. After a while, however, two canoes appeared, and this time the Indians evidently meant business. When they came within range, those of them who had rifles opened fire with such good aim that the bullets struck unpleasantly near the Little ramparts the two white men had hurriedly constructed after the first attack.

Taking careful aim, the Scotsman hit one of the Indians who, dropping his rifle, fell heavily on his face. Determined to make a landing, the Indians then plunged into the water, and, taking cover behind the canoes, swam, slowly pushing them towards the shore. Nearer and nearer they came, some of the natives -who were lying flat at the bottom of the canoes- keeping up a steady fire that was answered from the shore.

Presently, when the two defenders' situation began to look hopeless, the canoes slowly retreated, and when they were out of range, the swimmers

14 Publicada por Hodder \& Stoughton en 1945. 
clambered on board, and paddled to the far shore which could only be approached by water.

Next day, when the Scotsman and the German went to investigate if the coast was clear, they found several bodies lying near the shore were where the Indians had landed after their retreat. Among the dead were two women, who, like the others, must have been struck by bullets which had penetrated through the canoes behind which the natives had sought protection.

Added to the constant peril of attacks, the thought of having killed two women was too much for the Scotsman, who, soonafter this incident, left the wild Rio Baker for a safer part of the world. The German stayed on, to be knifed by a Chilote who had gone rampant with alcohol someone had mysteriously brought into the region.

El texto coincide a grandes rasgos con la versión difundida por Bridges, lo que resulta obvio por habérsela contado éste último directamente. Ataque sorpresivo de dos canoas de indígenas a las instalaciones de la estancia donde había dos empleados; respuesta de ellos parapetados en una trinchera improvisada; muerte de indígenas. Sin embargo, el escritor suizo entrega una serie de antecedentes que impresionan. En primer lugar dice que el empleado escocés abandona su trabajo, por haber quedado mal después del enfrentamiento, debido a que había matado a dos mujeres, sin haber tenido conciencia de ello hasta que fueron a ver el sitio donde desembarcó el grupo. El dato es perturbador, pues en las otras versiones donde se especifica a las víctimas -incluida la del mismo Bridges- se habla siempre de hombres fallecidos. El segundo dato que sorprende es la afirmación de que los empleados que enfrentaron al grupo canoero fueron un escocés y un alemán. Esto contradice las otras versiones, que mencionan la presencia de un chilote o chileno junto al escocés. Tschiffely afirma al final del relato que el alemán moriría posteriormente a manos de un chilote que enloqueció con alcohol que alguien habría internado misteriosamente en la zona. El tercer antecedente es que los empleados dejaron pasar un día y al siguiente fueron a verificar al sitio donde los indígenas acamparon después de la refriega, encontrando varios cuerpos entre los que se encontraban los de las dos mujeres.

Lo anterior indicaría que Bridges compartió con el escritor suizo más antecedentes que los que decide registrar en sus propios escritos. ¿Por qué habría hecho esto el estanciero?

El segundo registro literario pertenece a Francisco Campos Menéndez (1986) quien sólo menciona al pasar el asunto: [...]estaban siempre expuestos al ataque sorpresivo de nativos con armas de fuego; cabecilla era cierto notorio mestizo que cayó en su ley herido de muerte en una refriega. (p. 106)

Pese a lo concisa, la versión no deja de ser interesante por su densidad interpretativa, que propone un contexto donde la estancia de Hobbs \& Cía se ve enfrentada a frecuentes ataques de carácter imprevisto, utilizando armas de fuego y cuyos protagonistas son caracterizados genéricamente como nativos que obedecían a un jefe mestizo. Aquí la categoría mestiza del supuesto líder del grupo es sutilmente presentada como la responsable de la alterada actitud nativa.

Por otra parte, el autor habla de "una refriega". En el contexto de la frase, esta afirmación supone más de un altercado anterior. La refriega referida es la definitiva, pues termina con la muerte del líder. Implícitamente, el autor afirma que el hecho costó sólo una muerte. En contraste con lo planteado por Ivanoff en cuanto a que las versiones orales aumentan el número de nativos muertos, esta versión escrita los disminuye al mínimo posible.

El tercer registro literario proviene de la pluma de Félix Elías Pérez (1997) quien recoge tangencialmente el episodio que analizamos, cuando en su relato Chapuco Pérez -dedicado al cocinero chilote implicado en la muerte del empleado alemán en Bajo Pisagua-, escribe:

El [Chapuco Pérez] había visto cómo, sin siquiera un asomo de compasión ni justificación alguna, habían dado muerte a unos pobres alacalufes por el delito de querer cambiar algunas pieles de nutria por víveres y licores. (p. 97)

Esta versión, escueta también, pues el centro del relato es la historia de Pérez, nos plantea que este empleado chilote habría presenciado la matanza de los indígenas a manos de los otros empleados que ahora estaban con él con intenciones de querer eliminarlo. El autor-amparado en la licencia que otorga todo relato ficcionado-, coloca a su protagonista como testigo de un hecho anterior al que él mismo protagonizará. De este modo se busca justificar la actitud de recelo y rabia para con la Compañía en la que 


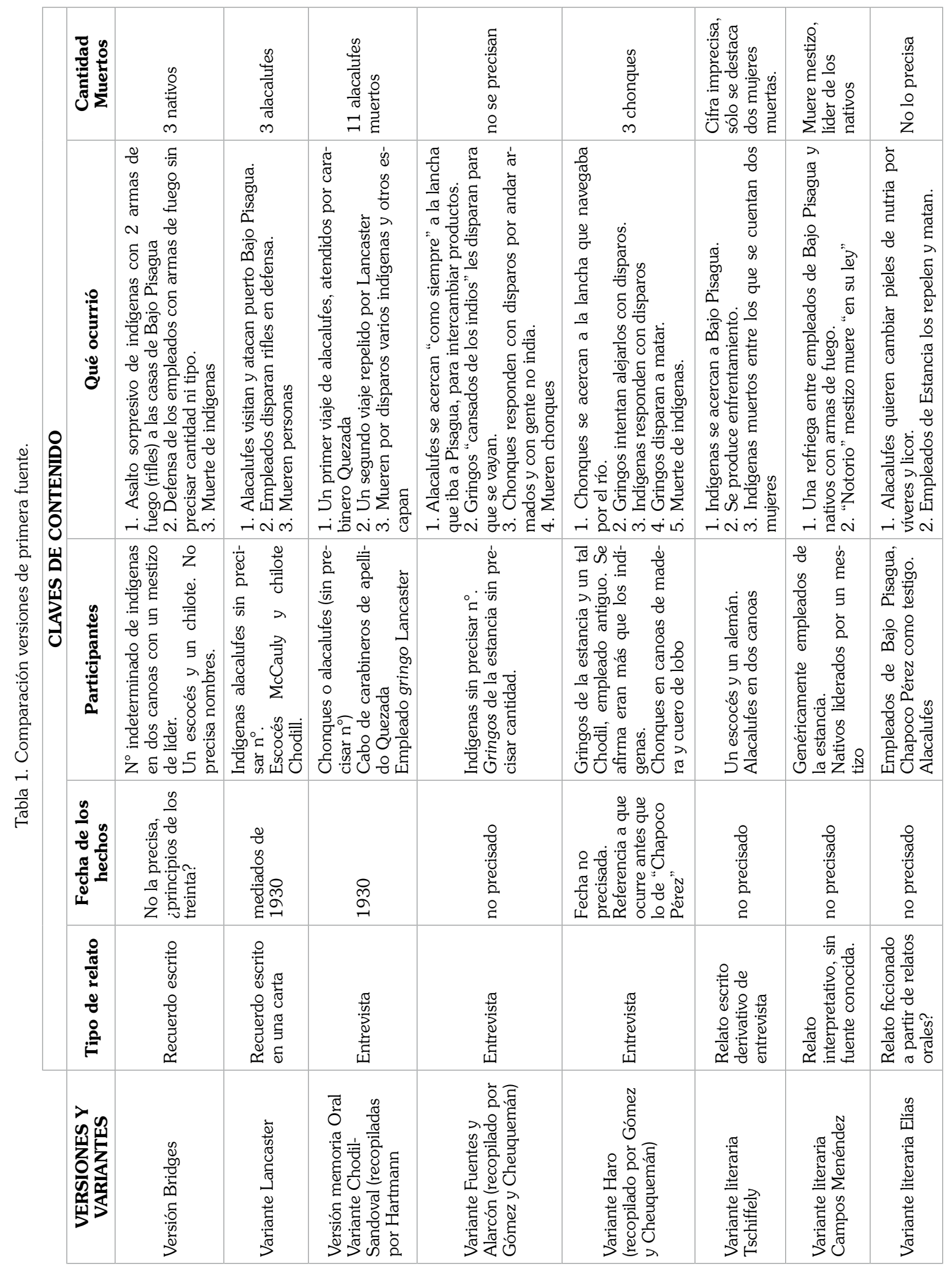


trabaja y los empleados leales a ella con los que se encuentra al momento de desatarse su propio drama. Sin embargo, en el texto se recoge nuevamente la versión del intercambio de subsistencia, agregando esta vez la búsqueda de licor además de víveres.

\section{LA VERSIÓN OFICIAL DE LOS HECHOS: LOS OFICIOS DE LA INTENDENCIA DE AYSÉN, DIRECCIÓN GENERAL DE CARABINEROS Y EL SUMARIO POLICIAL SEGUIDO POR EL COMANDANTE DE LA PREFECTURA AYSÉN ONOFRE PARRA}

Hasta aquí, tenemos un conjunto de versiones -escritas y orales- que testimonian la ocurrencia de un hecho de violencia en Bajo Pisagua, con resultado de muerte para indígenas alacalufes, que en el presente trabajo se consideran parte de la parcialidad Kawésqar, por encontrarse recorriendo un territorio cercano al golfo de Penas. Se propone que justamente por las diferencias y contradicciones que presentan entre sí, han conseguido mantener viva la historia de este violento suceso. Un dispositivo discursivo que ha operado también en el caso de la muerte de trabajadores chilotes a principios del s. XX en el mismo sector y que diera origen al cementerio Isla de los Muertos (Hartmann 1982; Mena y Velásquez 2000).

Sin embargo, estas mismas versiones, abren interrogantes que deben ser resueltas. Y uno de los caminos para ello es el análisis de la documentación oficial que sobre el episodio pudiera haberse generado. Ya se ha consignado que Bridges alude a una investigación efectuada por Carabineros, en tanto Sandoval indica un informe del carabinero Quezada. Se hacía preciso buscar antecedentes al respecto, para lo cual se indagó en el Archivo Nacional de Chile. ${ }^{15}$

El primer conjunto de documentos fue hallado en el Archivo Histórico y corresponde a oficios emitidos por la Intendencia de la Provincia de Aysén. Se trata de cuatro documentos, fechados entre abril y mayo de 1931 y dirigidos al Ministro del Interior de la época. ${ }^{16}$ El segundo grupo de documentos fue hallado en ARNAD.

15 Se visitaron el Archivo Histórico (AH) y el ARNAD, ambos ubicados en Santiago de Chile.

$16 \mathrm{AH}$, Fondo Intendencias. Intendencia de Aisén, vol único 1931. Hallados en 2010.
Lo componen dos providencias del Ministerio del Interior generadas en junio del mismo año, las que contienen los oficios de Intendencia antes mencionados, como también documentos oficiales emitidos por Carabineros de Chile, desde la Prefectura de Puerto Aysén y la Dirección Nacional ubicada en la capital del país. ${ }^{17}$

\section{III.1 La Intendencia de Aysén informa lo sucedido al Ministro del Interior}

El intendente de Aysén Luis Marchant recibe los primeros informes de lo sucedido en el puerto Bajo Pisagua a fines de marzo de 1931. Con estos antecedentes, no corroborados todavía por Carabineros de la Provincia, la autoridad emite el primer oficio al Ministro del Interior Octavio Reyes, el 16 de abril. En él informa que el subdelegado de Baker le ofició indicándole que el 12 de marzo dos canoas con indios chonquis se acercaron al puerto Bajo Pisagua perteneciente a la Compañía Estancias y Posadas Hobbs y Cía. Los empleados apostados en el lugar, creyendo que se acercaban por hambre, les ofrecieron pan. Los indígenas no lo habrían aceptado y exigieron les dieran sacos de harina. Ante la oposición de los empleados, los indígenas se reembarcaron alejándose y disparando armas de fuego sin dar blanco. Del hecho se dio aviso a la pareja de Carabineros más próxima, la que se habría trasladado al lugar. Hasta aquí el contenido del oficio.

El Ministerio del Interior recepciona este oficio recién el 26 de abril de ese año, ${ }^{18}$ y el Ministro instruye se ponga en conocimiento del mismo a la Dirección General de Carabineros. ${ }^{19}$ Entretanto, la Intendencia irá recabando más información y el 04 de mayo, vuelve a oficiar al Ministerio, con el fin de ampliar oficio 383[...], entregando nuevos datos enviados por el subdelegado de Baker. Aquí el Intendente afirma que hubo un intercambio de disparos entre los indígenas y los empleados apostados en Bajo Pisagua, con resultado de muerte de tres personas: dos indios y una india. El informe de abril quedaba así no sólo ampliado sino que desmentido en lo tocante a que sólo los indígenas habrían disparado y que

17 ARNAD, Fondo Ministerio del Interior. Providencias, Vols. 7881 y $7882,1931$.

18 ARNAD, Fondo Min. Interior, Minutas 1931, vol 7950.

19 Providencia 3464, del 30-04-31 
no hubo que lamentar muertes. Marchant informa también que el Comandante de Carabineros (de la Provincia) quien realizaba visita inspectiva al Baker, se habría trasladado al sitio para iniciar el sumario pertinente. Este segundo oficio se recepciona en Santiago el 15 de mayo, determinando el Ministro se informe nuevamente a Carabineros.

El 07 de mayo, el intendente Marchant solicita al Prefecto de Carabineros de Puerto Aysén, mayor Onofre Parra Toledo ${ }^{20}$, le remita dos copias del dictamen recaído en el sumario que dicha autoridad de Carabineros había instruido en el sitio del suceso. Ello indica que la primera autoridad regional estaba al tanto del término de la investigación; requería entonces copia de la resolución para remitirla al Ministerio. Una vez recibido el dictamen enviado por la Prefectura de Puerto Aysén, el intendente oficia al Ministro el 16 de mayo, adjuntando una copia del mismo. Informa además, que el original de dicho documento fue remitido a la justicia ordinaria para que tome conocimiento del hecho. El Ministerio, que recibe este oficio el 26 de dicho mes, instruye informar del mismo a la Dirección General de Carabineros, la que toma conocimiento recién el 02 de junio.

\section{III.2 Los informes de Carabineros de Chile}

Si bien fue la Intendencia de Aysén la que puso en conocimiento de lo ocurrido en Bajo Pisagua al Ministro del Interior, será Carabineros de Chile quien realmente trabajará para aclarar lo sucedido.

En efecto, el 29 de mayo la Dirección General de Carabineros oficia al Ministro transcribiendo otro oficio recibido desde la Prefectura de Puerto Aysén en el que se amplia un telegrama anterior ${ }^{21}$ de esa misma repartición donde se informaba lo sucedido y adjunta copia del sumario realizado, como también del dictamen recaído en esta investigación.

El oficio del prefecto de Aysén, mayor Parra indica que los sucesos con resultado de muerte ocurrieron el 17 de marzo de 1931. Los protagonistas habrían sido un grupo de indios alacalufes en número de doce, entre hombres y mujeres y niños con armas de fuego, cuyas pretensiones eran asaltar

20 Oficio 477, del 07-05-31. AH, Fondo Intendencias, vol único Intendencia Aisén.

21 Cuyo contenido no se conoce por no formar parte de los antecedentes que acompañan la Providencia. las bodegas de la Estancia Baker, resultando tres indios muertos, dos hombres y una mujer.

El mayor Parra, informa además que al encontrarse en visita oficial en el Baker, decide concurrir al punto indicado, procediendo a instruir un sumario administrativo, a partir del que se logra reconstruir los sucesos. La cuenta transcrita por el Director General de Carabineros termina informando que los antecedentes fueron remitidos al Juzgado de Subdelegación de Puerto Aysén, enviando copia del dictamen a la Dirección General de la institución.

Todo comienza a cobrar cuerpo. Existen dos importantes documentos emitidos en la Provincia de Aysén, el parte policial con el sumario y el Dictamen, ambos firmados por el mayor Parra en calidad de Prefecto el primero y Fiscal el segundo. El parte policial contiene la relación de los hechos, reconstruida por Carabineros a partir del interrogatorio a los protagonistas y testigos indirectos de los sucesos y la propia visita al sitio del suceso. En primer término se puede saber que además de los indígenas alacalufes, los empleados involucrados fueron Donald Macauley Mackay y Juliano Chodil Nain.

De acuerdo a la investigación de Carabineros los hechos ocurrieron como sigue: el 13 de marzo, llegaron a Bajo Pisagua dos canoas tripuladas por indígenas, posiblemente un grupo familiar completo a juzgar por la afirmación de que eran hombres, mujeres y niños. Se afirma que establecieron campamento en las cercanías de unos galpones donde se guardaba bencina. Traían consigo 20 o 30 perros. El día 14 desembarcaron todos en Bajo Pisagua pidiendo víveres, tabaco y cigarrillos, retirándose al campamento una vez que se les proveyó.

Continúa el parte informando que se habrían cambiado de campamento, construyendo una ruca, dos millas al oeste del puerto 22 por la misma orilla de éste, permaneciendo en el sitio todo el día 15, sin molestar. Al día siguiente, dos de los empleados de la estancia, Arturo Warrick y Eduardo Lancaster, se embarcan en la lancha de la Estancia y emprenden viaje a Puerto San Carlos, ubicado 80 km río arriba, dejando en las instalaciones a Macauley y Chodil al cuidado de las casas y bodegas, donde había intereses por más de medio millón de pesos. Al percatarse los indígenas del zarpe de la lancha, deciden volver al muelle haciendo ademanes de hostilidad,

22 Corresponderían a 3,22 km. 
negándose a recibir lo que los cuidadores les ofrecían para finalmente obligar a ambos empleados a encerrarse en las casas, por verse amenazados. Los indígenas se retiraron a su campamento ese día al anochecer. El 17, los dos empleados decidieron no dejar que los indígenas nuevamente desembarcaran. Cuando éstos comenzaron a acercarse nuevamente les gritaron e hicieron señas para que regresaran, diciéndoles que ya no tenían nada más que darles. Los indígenas continuaron acercándose, por lo que Macauley decidió disparar un tiro de carabina al agua. Lejos de amedrentarlos los habrían enfurecido más y-dice el parte-regresaron a su campamento, gritando desaforadamente, entendiéndoles que decían: indiano muy bravo, indiano malo, escopeta carpa. En el campamento desembarcaron a una de las mujeres y a los niños y volvieron a embarcarse en una de las canoas con rumbo a las casas, portando una carabina Winchester y una escopeta. Ante esto, los dos empleados reflexionaron rápidamente que si dejaban que desembarcaran, serían hombres muertos y las instalaciones serían saqueadas e incendiadas, por lo que decidieron repelerlos usando para ello una carabina (la que ya había percutado el mismo Macauley) y un revólver, manipulado por Chodil. Eligieron como lugar de operación un pequeño morro que se encuentra a 200 metros del Puerto, entre éste y el campamento de los indígenas.

Cuando la canoa pasó frente al morro, los empleados volvieron a gritarles que se retiraran, pero fue infructuoso y Macauley disparó nuevamente al agua. La respuesta fueron disparos de carabina y escopeta que no dieron en los empleados. Macauley volvió a disparar cuatro tiros sin hacer blanco. La canoa seguía avanzando a la costa ya muy cerca de ella. Entonces -afirma el parte- los empleados habrían disparado buscando hacer blanco, en especial sobre aquellos que llevaban las armas de fuego. Momentos después tres de los indígenas se habrían echado al agua, tomados de las bordas de la canoa y los demás se parapetaron dentro de la embarcación. Ésta, sin impulso humano, quedó a merced de la corriente y se alejó. Una vez que se sintieron seguros, los que se encontraban dentro de la canoa, ayudaron a los demás a reembarcarse y se fueron al campamento, donde permanecieron una hora al menos, para luego retirarse hacia el canal Huemules.

Como los indígenas dejaron abandonada una de las canoas y a varios perros, los empleados atestiguaron que creyeron que aún permanecía allí parte del grupo por lo que no se atrevieron a explorar el lugar. Entretanto, la lancha que había remontado el río el día 16, regresó el 22 y enterándose de lo sucedido, volvió a subir para dar cuenta a la pareja de carabineros apostados en La Colonia, el cabo $2^{\circ}$ Rafael Quezada López y carabinero José Navarro Tamayo, los cuales se trasladaron al lugar en la misma lancha de la estancia y el 25 de marzo tomaban conocimiento de la situación y recorrían el campamento indígena, constatando la presencia de tres cadáveres, dos hombres y una mujer, además de una canoa y algunos perros. De acuerdo con el parte, en esa oportunidad no se procedió a sepultar los cadáveres. Ello se hizo cuando el mayor Parra llegó al lugar, casi un mes después de ocurrido el incidente, el 16 de abril de 1931, encontrando sólo un cadáver, pues los otros dos habrían sido consumidos y diseminados por los perros que allí quedaron, siendo buscados infructuosamente.

El mayor Parra, decide no incautar las armas de los empleados de la estancia, en atención a que constituían la única defensa en caso de que se repitiera un nuevo ataque por parte de los indios. El Prefecto Parra, informa finalmente que de acuerdo con el procedimiento, se detuvo a los dos involucrados por la responsabilidad que pudiese caberles en las muertes constatadas, pero deja constancia que a su juicio habrían actuado en defensa propia, tanto de sus vidas como intereses a su resguardo, ante la superioridad en número de los indígenas y el estado anímico que presentaban enfurecidos como fieras salvajes. Por lo demás -indica el Prefecto- los empleados presentaban buena conducta anterior. Todo ello indicaba que no tenían responsabilidad criminal.

Como se puede observar, los sucesos fueron mucho más complejos de lo que se ha conservado en los registros escritos y en la memoria oral. El grupo alacalufe, compuesto por adultos y niños de ambos sexos, organizó campamento en las cercanías, pidió (o tal vez intercambió productos, no puede saberse a partir del parte policial) alimentos, los que se les dieron sin mayores inconvenientes al principio, pero luego al insistir una segunda vez, los empleados les negaron y comenzó a tensarse la situación hasta derivar en el asesinato de tres miembros del grupo alacalufe, entre los que se contaba una mujer.

Tampoco la inhumación estuvo exenta de condiciones dramáticas: un mes después del hecho, 
se dio sepultura sólo a uno de los cuerpos, debido a que los otros habrían sido consumidos por los perros. ¿Qué cuerpo fue enterrado? ¿la mujer o uno de los hombres? Esto tal vez no podrá saberse nunca.

Una vez efectuada la investigación, el mismo mayor Parra, ahora en calidad de Fiscal de la Subdelegación de Puerto Aysén, debe emitir un dictamen respecto a la misma y a la responsabilidad que pudo caberle a los empleados Macauley y Chodil. El documento está organizado en cuatro puntos de antecedentes, cuatro consideraciones y una resolución final.

El primer punto de antecedentes consigna que el Prefecto se enteró de los hechos estando de visita inspectiva en Baker. Que Chodil, uno de los involucrados, declaró en el sumario que él y Macauley eran los únicos testigos presenciales del suceso y que por considerarse en peligro de muerte, dispararon a los indígenas, matando a tres de ellos, dos hombres y una mujer. Chodil realizó esta declaración en La Colonia, pues el mayor Parra indica que después de oírla se trasladó a Bajo Pisagua para constatar los dichos del empleado.

El segundo punto indica que a partir de las declaraciones de Chodil y Macauley, se supo que los indígenas llegaron el día 13 de marzo y hostilizaron a los empleados pues querían apoderarse de las mercaderías del puerto.

En el tercero, se alude a la declaración de Eduardo Lancaster Soly ${ }^{23}$, quien afirmó haberse enterado de lo sucedido a su regreso desde San Carlos, decidiendo entonces volver a dicho puerto para desde allí subir a dar cuenta a Carabineros destacados en La Colonia, con los que vuelve a Bajo Pisagua y recorre el campamento indígena encontrando tres cadáveres tapados con cueros de lobos y como seis a siete perros también abandonados en la costa.

En el cuarto punto se reconstruyen los últimos dos días de confrontación basándose en los antecedentes que el propio fiscal Parra recoge en terreno y en las declaraciones emitidas por Lucas Bridges $^{24}$ y también en las de los carabineros Quezada y Navarro que a fines de marzo acompañaron a Lancaster para verificar lo acontecido. La reconstitución plantea que al enterarse los indígenas que

23 En el documento el segundo apellido de esta persona aparece escrito como Solly. Providencia 5161, p. 2.

24 En el dictamen el nombre del estanciero se registra como: Lucas Britg Varder. Providencia 5161, p. 2. sólo hay dos empleados, deciden acercarse al muelle con intención de asaltarlo. Al ser conminados a retirarse por los dos empleados que les dispararon un tiro, vuelven a su campamento para regresar luego con dos armas de fuego y otras armas como hachas y arpones, en evidente estado de excitación bélica. Los empleados vuelven a realizar disparos de advertencia, pero al recibir por respuesta disparos de los alacalufes, apuntan nuevamente, pero que no ha habido el ánimo preconcebido de dar muerte a esos indios. El Fiscal cita además que Bridges declara en defensa de sus empleados, diciendo que han tenido una conducta intachable todos los años que han trabajado para él y que en esta oportunidad habían cumplido con su deber de resguardar los intereses de la compañía que ascendían en Bajo Pisagua a medio millón de pesos.

Entre los considerandos se lee que se ha comprobado el ataque de los indígenas al puerto con la intención de apropiarse de los víveres almacenados allí; el actuar a la defensiva de los empleados; y la muerte de tres indígenas, entre ellos una mujer. Que por el ánimo hostil de los indígenas debido a su absoluta falta de civilización, a lo aislado del puerto Bajo Pisagua y a las circunstancias de la muerte de los indígenas, se desprende que hubo causas suficientes para que dichos empleados se defendieran con las armas. Que había quedado demostrada la irresponsabilidad criminal de los dos empleados por haber actuado en propia defensa y no eran personas de mala conducta anterior. Que los empleados obraron impulsados por un miedo insuperable a morir a manos de los indígenas, que en definitiva son personas sin civilización, aislados del resto de la humanidad; además de ello el uso de las armas por parte de los empleados era correcto toda vez que se comprobó una agresión ilegítima por parte de los alacalufes, un uso racional de ellas y falta de provocación de parte de Chodil y Macauley; finalmente, el estar en inferioridad numérica ante atacantes de reconocida temeridad, por su falta de cultura y civilización.

La resolución del Fiscal en atención a lo antes indicado, fue la siguiente:

Esta Fiscalía estima que, moral y legalmente no existe responsabilidad criminal de parte de Juliano Chodil Nain y Donald Macauley Mackay, en la muerte de dos indios y una india; en virtud de los incisos cuarto y noveno del art. décimo del 
Código Penal, por lo que considera que ambos deben ser absueltos por la Justicia Ordnaria.

Pero no termina aquí la documentación oficial. En su respuesta a la Providencia 3464 del Ministro del Interior, el Director General de Carabineros, General de Brigada Ambrosio Viaux Aguilar, oficia el 30 de mayo que en relación al caso de Bajo Pisagua, informado por la Intendencia de Aysén en abril, su institución dio cuenta ampliamente sobre el particular y le aclara que el contenido del oficio de la Intendencia -el primero que se analizó más arribano se ajusta a los hechos debido a que el intendente fue informado por el subdelegado interino del Baker, pues el titular se encontraba con permiso. ${ }^{25}$ Dicho funcionario habría recabado información basándose en rumores que corrían en el pueblo de Backer, según afirma la autoridad de Carabineros, defendiendo a renglón seguido la veracidad de los antecedentes entregados por dicha institución.

Un último documento aún, será el que cierre la saga de antecedentes oficiales sobre el caso de Bajo Pisagua. Corresponde al oficio 625 de 18 de junio de 1931, emitido por el intendente Marchant en el que informa al Ministro que habiendo recibido copia del oficio de la Dirección General de Carabineros, deja en claro que la Intendencia remitió al Ministerio el dictamen recaído en el sumario practicado en el sitio del suceso con fecha 16 de mayo de dicho año. De este modo, Marchant se desentiende del primer oficio donde entregaba información errónea, y se apega al dictamen del Fiscal, donde se relata las circunstancias y el desenlace del episodio.

Como se puede apreciar, la relación oficial de los hechos se basa en la investigación sumaria practicada por el Prefecto Parra en el terreno mismo, tomando declaraciones a los protagonistas, testigos indirectos y carabineros que participaron en el primer procedimiento que confirmó la muerte de los indígenas. Sin embargo, no se debe pasar por alto que esta versión descansa en testimonios de solo una parte de los involucrados. La versión de los indígenas sobrevivientes no fue recogida. Es cierto que el grueso del grupo se retiró después de la refriega hacia el denominado canal Huemules,

25 No ha sido posible conocer el nombre de aquel Subdelegado interino. Se tiene certeza sí que el Subdelegado oficial ese año era Luis Antonio Labra Sepúlveda, nombrado el año 1930. Providencia 3126, abril 1931, ARNAD, Fondo Ministerio del Interior, Vol 7869. como lo indica el Prefecto. Pero carabineros no los buscó, no era necesario aquello, ya que su falta de civilización -como el mismo Prefecto lo afirma- los colocaba en una condición humana inferior, irracional, donde todo testimonio habría estado mediado por esa discapacidad cultural que el propio policía se encargó de recalcar en su escrito.

$\mathrm{Y}$ justamente por recoger los testimonios indicados, esta versión oficial coincide con la de Lucas Bridges en cuanto a considerar como atacantes a los alacalufes, pese a que deja establecido que los empleados de la Estancia dispararon primero sus armas. De acuerdo al relato, estos primeros disparos, provocaron el encono de los indígenas, que no iban armados y por ello volvieron a su campamento por armas de fuego y también por armas y herramientas tradicionales como arpones y hachas. Por otro lado, la investigación policial da luz respecto al momento en que el estanciero se habría trasladado al sitio: recién un mes después de ocurridas las muertes.

\section{UN REGISTRO FOTOGRÁFICO CLAVE}

Circula entre las fotografías históricas de la región de Aysén una que corresponde directamente al caso de Bajo Pisagua. Ello porque cuenta la imagen con una leyenda manuscrita a modo de título donde leemos: Entierro de indios alacalufes. Aquí está el dueño de la Estancia Backer Mr. Lucas Brige.

La imagen muestra a tres personas en actitud de descanso frente a una excavación en la que se alcanza a ver una esquina de lo que parece ser un ataúd de madera. A la izquierda en primer plano se aprecian troncos posiblemente arrastrados por el río y suelo pedregoso, lo que parece indicar una pequeña playa en la ribera del río. Al fondo se aprecia con dificultad, parte del río. De las tres personas retratadas es posible distinguir al menos dos que de hecho alguien marcó con número. El 1, por el tipo de uniforme, debe ser el Prefecto Parra, en tanto que el 2, es claramente Lucas Bridges. La tercera persona es uno de los dos carabineros destacados en La Colonia. Este testimonio gráfico permite confirmar que Lucas Bridges se trasladó a Bajo Pisagua junto con el mayor Parra y no antes.

La actitud de cada uno de los tres retratados es llamativa. De los dos uniformados, el oficial mantiene postura militar pareciendo posar; el carabinero al 


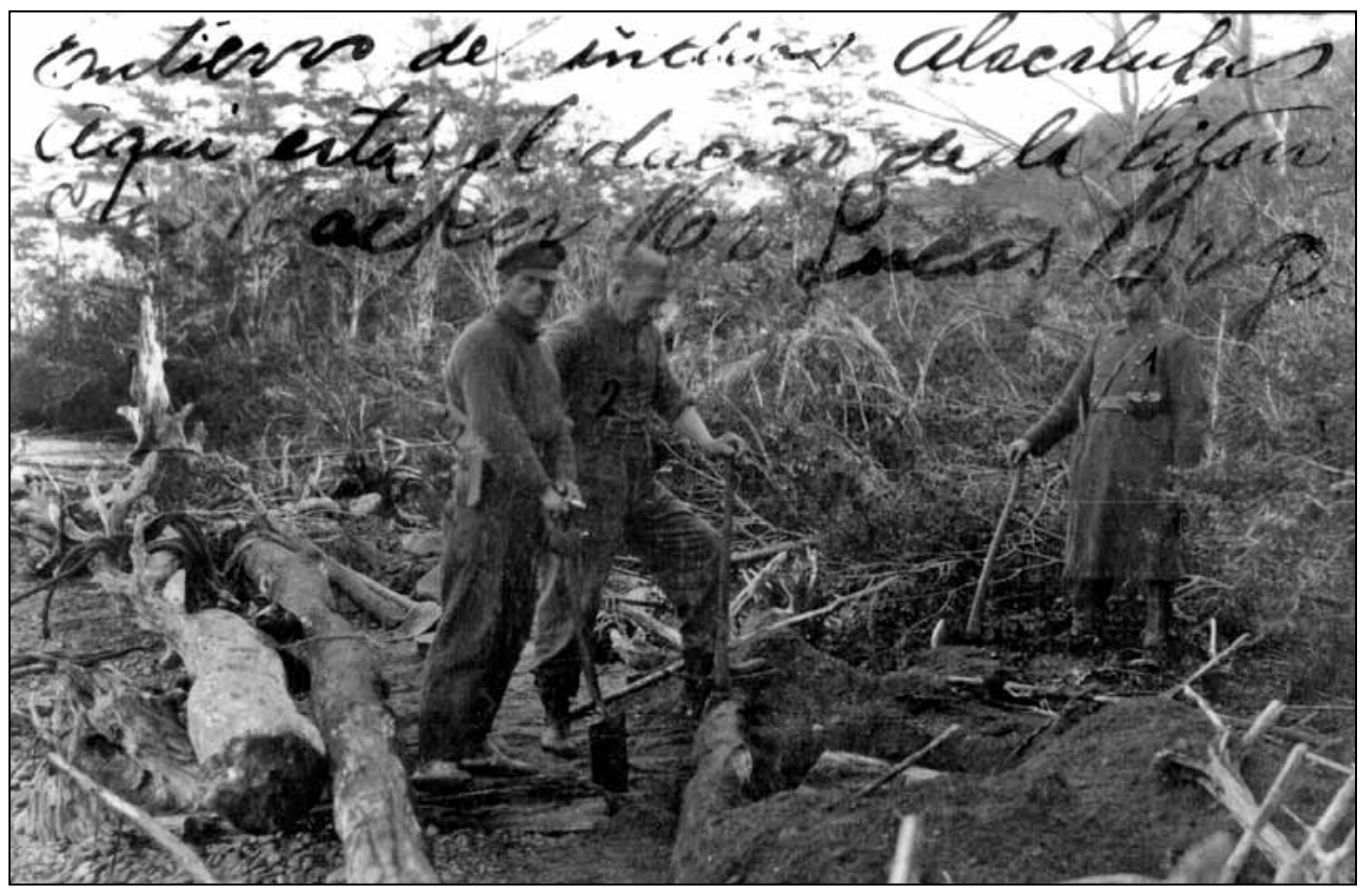

Fig. 2. Fotografía inhumación de indígena(s) en las cercanías de Bajo Pisagua, 1931.

lado de Bridges, en actitud de descanso, muestra una postura indefinida y el cigarro en su mano izquierda, refuerza la imagen de relativa indiferencia frente a la situación. Ambos uniformados observan la cámara fotográfica. Lucas Bridges en cambio, se ve cabizbajo. No mira a la cámara, está observando la fosa que han abierto.

Si bien la fotografía no permite identificar cuántos cuerpos están siendo sepultados, sabemos por el parte policial que se trataría sólo de un cadáver. Ello en todo caso se contradice con el título de la fotografía que ha sido consignado, donde se indica la sepultación de indios alacalufes.

\section{CONCLUSIONES}

El caso de Bajo Pisagua, se ha mantenido en la memoria histórica de la región de Aysén gracias a relatos escritos y orales que han conservado en mayor o menor medida los elementos clave que le dan sentido: el enfrentamiento entre un grupo canoero alacalufe con empleados de la Estancia Posadas Hobbs y Cía., cuyo resultado fue la muerte de tres indígenas. Los relatos cercanos a la historia de la Compañía ganadera liderada por Bridges, reivindican el suceso como demostración de los sacrificios por colonizar y hacer producir el área; aquellas alojadas en la memoria popular, rememoran la suerte fatal corrida por los indígenas a manos de los intereses personales y corporativos representados por la compañía ganadera y se relatan como un ejemplo entre varios de un periodo de violencia e impunidad de dicha empresa. Entre ambos extremos hay aún otros registros del hecho más o menos objetivos que han contribuido a mantenerlo vigente.

Al consignar y analizar la versión oficial del suceso, contenida en oficios y registros públicos, se ha pretendido contribuir a esclarecer las circunstancias del mismo, despejando de este modo los vacíos e inconsistencias de las versiones hasta ahora conocidas.

Ahora bien, este suceso aparece como el primero de una serie de hechos que terminará con la desaparición de las instalaciones del puerto Bajo Pisagua -hacia fines de 1931- y el consiguiente abandono del Baker medio y Bajo como ruta de comunicación al Pacífico, obligación que la empresa había aceptado en todos los decretos de concesión que la beneficiaron. Abandonar dicha vía era un objetivo que la empresa a cargo de Bridges perseguía desde fines de la década del veinte y que logra recién a mediados de los treinta. 
La crudeza y dramatismo del acontecimiento, de acuerdo con lo relatado en el parte policial hace creíble lo que consignara Tschiffely respecto a la renuncia del escocés Macauley, debido a que se entera que entre los muertos había mujeres. El parte policial, así como uno de los oficios del intendente Marchant afirman que hubo sólo una mujer muerta, lo que sugiere que la información sobre dos mujeres muertas, registrada por el escritor suizo sería errónea. Por otra parte, la misma investigación policial, refuta el relato del poblador Sandoval (1982) que afirmaba que fueron once los indígenas muertos.

Bridges en tanto, al parecer resintió fuertemente este suceso. Se ha atribuido a su particular sensibilidad con el mundo indígena el que se lamentara de las consecuencias de este episodio en sus escritos. Pero es dable preguntarse por qué al escribir, el estanciero omite que entre los muertos había una mujer, si a Tschiffely le habría confirmado este hecho durante la entrevista; por qué pasa por alto las eventuales relaciones de intercambio entre los canoeros y los empleados de Bajo Pisagua, que aparecen con tanta claridad en los relatos orales y como caridad de los empleados en la investigación de carabineros; o por qué omite el lapso de tiempo transcurrido entre la ocurrencia del hecho y su apersonamiento en el sitio. Tampoco resultan claras las razones que tuvo para tratar con ambigüedad y confusión la fecha en que todo ocurrió. Si se piensa, por ejemplo, una atendible dificultad para recordar sucesos del pasado, habría entonces que relativizar todas y cada una de las fechas que entrega en sus escritos. Lo ocurrido en Bajo Pisagua en 1931, pudo haber quedado sólo en la memoria oral a partir de los rumores que rápidamente corrieron por todo el Baker. Pero la presencia de Carabineros en el sector, obligó a la estancia a informar formalmente lo sucedido y gatilló una investigación policial que lo hizo trascender más allá de las fronteras administradas por la compañía.

En la decisión de Bridges de incluir este suceso en su autobiografía puede haber influido la necesidad de contrarrestar la versión oral que corrió como reguero de pólvora entre peones y pobladores. Con el tiempo dicha versión sería considerada como la más verosímil justamente por estar ella escrita. De este modo su autor lograba un doble objetivo: presentar como parte de su epopeya empresarial, un drama humano que no fue posible evitar y que lo afectó emocionalmente; $y$ establecer un velo en torno a las circunstancias que lo produjeron, así como las consecuencias trágicas derivadas del mismo.

No se pone en duda aquí el lamento expresado por las palabras de Bridges. De hecho el testimonio gráfico que se ha presentado lo retrata cabizbajo frente a la fosa, abatido ante la situación. Lo que sí se advierte es que posiblemente el estanciero no sólo lamentó lo sucedido, también hubo de sentir vergüenza al enterarse y luego constatar que entre los muertos había una mujer. Aquello sí resultaba altamente complejo para dejarlo por escrito y complicaba sobremanera la versión oficial que la compañía a su cargo decidió defender: el ataque sorpresivo de los indígenas y la defensa necesaria de los empleados.

Ahora bien, la ocurrencia de este trágico hecho no sólo marcará un antes y un después en la historia del emprendimiento ganadero liderado por Bridges en el Baker; también da cuenta del drama que las últimas familias kawésqar que recorrían y habitaban en el extremo norte de su territorio ancentral estaban viviendo: su dependencia de enclaves "occidentales" como Bajo Pisagua, a los que se acercaban en busca de alimentos y enseres que les eran regalados o entregados por los cuidadores -según la versión registrada en la relación policial- sugiriendo un accionar mendicante de parte de dichas familias. No se puede descartar sin embargo, la idea de un intercambio comercial desigual entre estas familias kawésqar y los empleados de Hobbs \& Cía. ${ }^{26}$

El episodio que aquí se ha analizado permite asimismo postular que en el área del canal Baker y hasta la desembocadura del río homónimo hubo presencia de familias kawésqar, que conocían y utilizaban sectores costeros para levantar campamentos residenciales temporales. De hecho, el parte policial entrega información sobre el campamento levantado por los canoeros a unos tres kilómetros al Oeste del puerto, durante los cinco días que permanecieron en el área; y también sobre su retiro hacia un denominado canal Huemules, topónimo que actualmente no se registra ni conoce en el sector. Tal vez dicho canal corresponda al actual fiordo Steffen, donde existe un puerto Huemules y también un río Huemules que desagua el glaciar que da nombre al fiordo. Todo ello abre una oportunidad a la arqueología histórica

26 En orden a confirmar o descartar esta hipótesis, se deberá indagar sobre el mercado de pieles hacia fines de los años veinte y principios de los treinta. 
para pesquisar sitios canoeros en las cercanías de Bajo Pisagua y hacia el fiordo antes indicado.

Pero ¿habrá sido este hecho de sangre que costó la vida a dos hombres y una mujer kawésqar, el causante de un despoblamiento definitivo del área por parte de las últimas familias alacalufes que la frecuentaban?

Así parece sugerirlo Grosse, quien en 1949, casi veinte años después del hecho, visitó el área a bordo del buque Guardacostas Galvarino de la Armada Chilena. En su relato (publicado en 1990), da cuenta de un antiguo puerto ubicado en el delta del río Baker: Al final de la ensenada encontramos los restos de un muelle y unas casas, una cocina quemada, planchas de zinc, alambres y otros enseres desparramados desordenadamente por el suelo. (p. 253). Y más adelante agrega: No hemos visto embarcación alguna; parece que esta región es muy solitaria, incluso para los alacalufes. ( $p$ 255). Tal vez las almas de los asesinados en aquel puerto abandonaron el frío y la humedad que habita aquellos paisajes. Tal vez el explorador no conoció la historia ocurrida allí a principios de 1931. O de conocerla se cuidó de consignarla por prudencia o respeto. El hecho concreto es que afirma no identificar presencia humana en el área, ni de occidentales ni de indígenas canoeros.

La sentencia de Lancaster Soly en torno a los alacalufes: "nunca más volvieron", se elevaría entonces como cierta. Pero como la memoria oral del Baker no afirma lo mismo, queda en el aire la pregunta: ¿Existe la leve posibilidad que esas últimas familias sobrevivieran, incorporándose en silencio al flujo colonizador que formó dos décadas después la localidad costera de Caleta Tortel?

\section{AGRADECIMIENTOS}

Agradecemos al Centro de Investigación en Ecosistemas de la Patagonia (CIEP), por el espacio para desarrollar estas investigaciones históricas. A Enrique Martínez S. por su constante apoyo en la reflexión y revisión del manuscrito. A Francisco Mena por la revisión y certeras observaciones al documento final. A Fabien Bourlon por permitirnos acceder a la versión Tschiffely en inglés y discutir algunas de las ideas contenidas en este trabajo. A Gustavo Saldivia por la elaboración del mapa contextual. A Joaquín Bascopé por facilitarnos la cita en inglés de la autobiografía de Lucas Bridges. Alan Olguín, funcionario de ARNAD, por el apoyo para encontrar los volúmenes del año 1931. A Eugenia Mancilla por la colaboración en el hallazgo de documentos. A la Sociedad de Historia y Geografía de Aysén por permitirnos acceder a su Archivo Documental.

\section{BIBLIOGRAFÍA}

AGUILERA, O. y P. ERRÁZURIZ. 1996. Fotografías Los Nómades del Mar. Exposición MNBA, Santiago. (http:// www.kawesqar.uchile.cl/exposicion/paz/nomadas.pdf, consultado 29-02-12).

CAMPOS, F. 1986. El Baker. Un territorio bravío. Autoedición. Santiago.

CÁRDENAS, R. 1996. Chiloé. Diccionario de la lengua y de la cultura. Autoedición. Castro.

ELÍAS, F. 1997. Acuarelas del Baker. Autoedición. Coyhaique.

GÓMEZ, R. y J. CHEUQUEMÁN. 2004. De Pueblo Nuevo a Cochrane. Historia y tradiciones. Autoedición. Cochrane.

GROSSE, A. 1990. Expediciones en la Patagonia Occidental. Hacia la Carretera Austral. Editorial Andrés Bello, Santiago.

HARTMANN, P. 1982. Antecedentes para un Plan de desarrollo de Puerto Yungay. Informe de práctica profesional. Fac. de Arquitectura y Urbanismo, Universidad de Chile, Santiago. MS.

IVANOFF, D. 2004. Lucas Bridges, "El Señor del Baker". Autoedición. Chile Chico.

MARTINIC, M. 1977. Ocupación y colonización de la region septentrional del antiguo Territorio de Magallanes entre los $47^{\circ}$ y $49^{\circ}$ Sur. Anales del Instituto de la Patagonia 8:5-57

MENA, F. y H. VELÁSQUEZ. 2000. Isla de los muertos: mito y realidad. Anales del Instituto de la Patagonia, Serie Ciencias Humanas 28: 53-72.

OSORIO, M. 2007. Aisén territorio y Aisén humanidad. Itinerario de una construcción social de la(s) identidad(es) regional(es). En: Otras Narrativas en Patagonia. Tres miradas antropológicas a la region de Aisén. Ediciones Nire Negro, Coyhaique.

2009. Apuntes etnográficos para Estudio Identidad Regional. Gore-Ilpes Cepal. MS.

SAAVEDRA, G. 2002. Paso al sur: el litoral norte de Aysén: poblamiento, etnografía y desarrollo. Memoria de título para optar al grado de Antropólogo social. Universidad de Chile. MS 
TSCHIFFELY, A. F. 1945. This way southward. An account of a journey through Patagonia to Tierra del Fuego. Hodder \& Stoughton Limited. Londres.

\section{Documentos Inéditos}

ARCHIVO HISTÓRICO NACIONAL. Fondo Intendencias. Intendencia de Aisén, volumen único 1931. Santiago. ARCHIVO NACIONAL DE LA ADMINISTRACIÓN. Fondo Ministerio del Interior, Minutas Sección Gobierno, volumen 7950, Correspondencia recibida año 1931, Santiago.
ARCHIVO NACIONAL DE LA ADMINISTRACIÓN. Fondo Ministerio del Interior, Providencias, volúmenes 7879, 7881, junio 1931; volumen 7899, noviembre 1931. Santiago.

BRIDGES, E. L.. Memorias del Baker. Escrito alrededor de 1946, 7 p. Recopilación Duncan Campbell \& Gladys Grace, www.patlibros.org.

BRIDGES, E. L.. Sinopsis del trabajo realizado en el Baker durante 28 años. Escrito alrededor de 1946, 8 p. Recopilación Duncan Campbell \& Gladys Grace, www.patlibros.org. HARTMANN, Peter. Entrevista a Reinaldo Sandoval Cifuentes. Transcripción literal. 